http://jmscr.igmpublication.org/home/ ISSN (e)-2347-176x ISSN (p) 2455-0450 crossref DOI: https://dx.doi.org/10.18535/jmscr/v7i8.64

Journal Of Medical Science And Clinical Research

\title{
Transoral Endoscopic Thyroidectomy: A Case Series of 18 Cases
}

\author{
Authors \\ Padmasen Vishnu Ranbagle, Vivek Kumar Singh, Gaurish Borkar, Atul Kale, Puneet S \\ Department of General Surgery, \\ Byramjee Jeejeebhoy Government Medical College, Pune, Maharashtra, Pin 41101
}

\section{Introduction}

Thyroid surgeries have evolved over time from late $19^{\text {th }}$ century where patient safety and mortality was a concern to the present age, where various minimally invasive and scarless surgeries are evolving.

Most of the endoscopic thyroid surgeries are based on the principle of hiding the scar within neck creases or just shifting the neck scar to axilla, areola of chest of the patient.

Vestibular approach to thyroid is truly a NOTES surgery which absolutely leaves no scar and addresses the issue of manoeuvrability faced during sublingual transoral approach.

Our novel study is an attempt to access thyroid gland via oral vestibule to achieve a scar free thyroidectomy.

\section{Aims and Objective}

To explore the feasibility, safety and effectiveness of resection of thyroid gland via transoral vestibular approach.

\section{Review of Literature}

Wilhelm and metzig ${ }^{1}$ performed the first endscopic minimally invasive thyroidectomy through sublingual approach in 8 patients in 2011.
Transoral thyroidectomy was first reported by Nakajo et el $(2013)^{2}$ who used gasless technique by using krischners wire.

In 2018 Anuwong $^{3}$ et al published a retrospective data of 425 patients comparing transoral vestibular thyroidectomy with open conventional approach and concluded that "The TOETVA was performed as safely as OT, requires only conventional laparoscopic instruments, and avoids incisional scars; thus, the approach may be an option for select patients."

\section{Research Methodology \\ Inclusion Criteria}

- Patients presenting to surgery OPD with thyroid swelling.

- Willing to take part in the study and consenting for the procedure.

\section{Exclusion Criteria}

- Previous neck surgery

- Recurrent thyroid swelling

- Thyroid malignancy

- Unfit for surgery

- Not willing to take part in study

- Lost on follow up

Study Design: Prospective observational study

Sample Size: 18

Duration of study: Oct' 2017 - Oct'2018 


\section{JMSCR VoI||07||Issue||08||Page 372-377||August}

\section{Methodology}

Patient willing to take part in the study were subjected to transoral thyroidectomy through vestibular approach, after taking due consent.

Data related to patient's age, sex, indication for surgery, operative time, intraoperative blood loss, the need to convert to open surgery, length of hospital stay and post-operative pain, morbidity and complications were collected preoperatively, intraoperatively and on Day 7, One month, and 6 months post operatively.

Manchester scar scale was used to evaluate and grade post operative scar after 1 month and Visual analogue scale was used to grade post operative pain on day 1,2 and 3 .

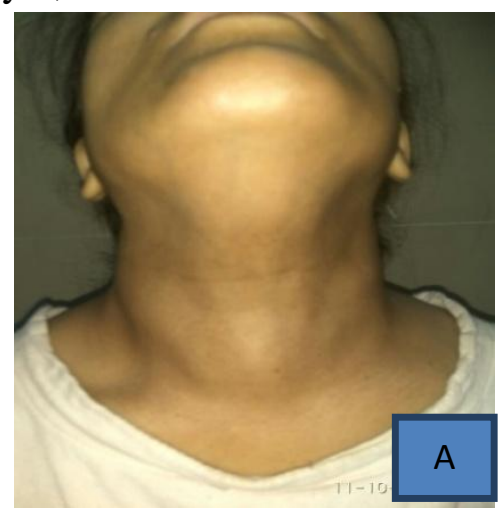

A- Preoperative photo showing right thyroid swelling

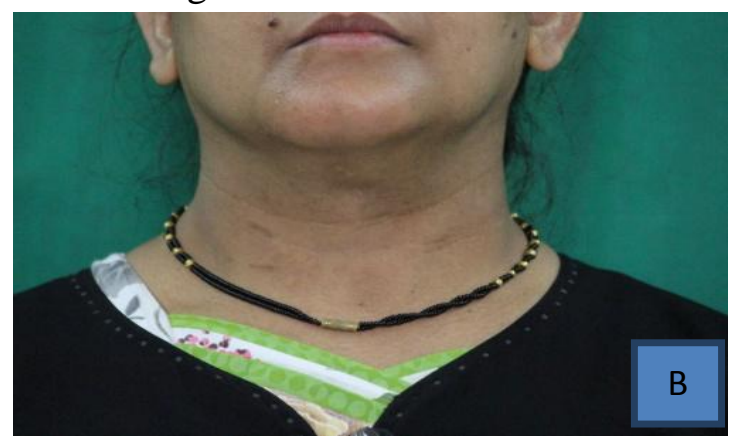

B. Post operative photo (MSS5)

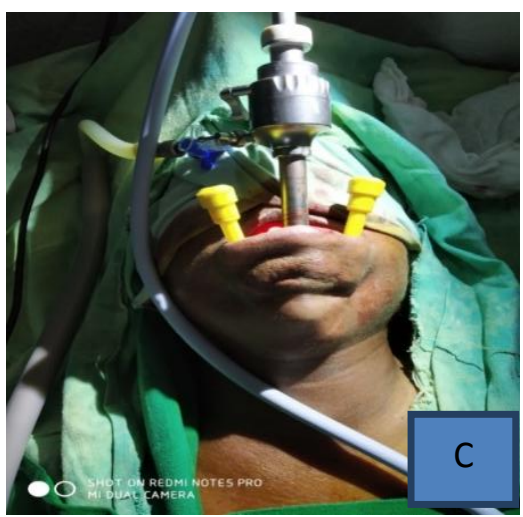

C. Port position in lower vestibule

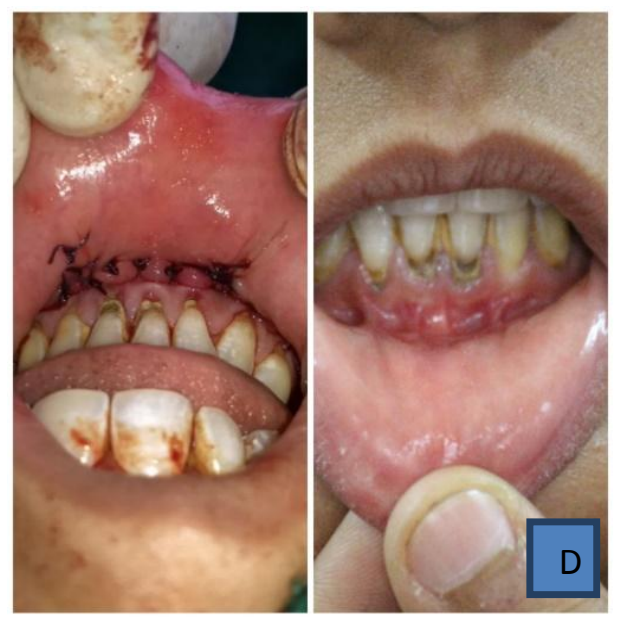

D. Immediate post op and 1 month after follow up of sutured lower vestibule

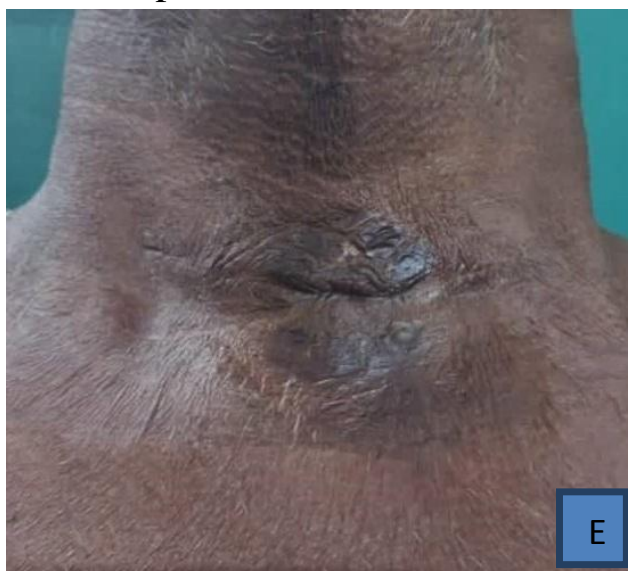

E. Neck abscess wound on 1 month follow up (MSS11

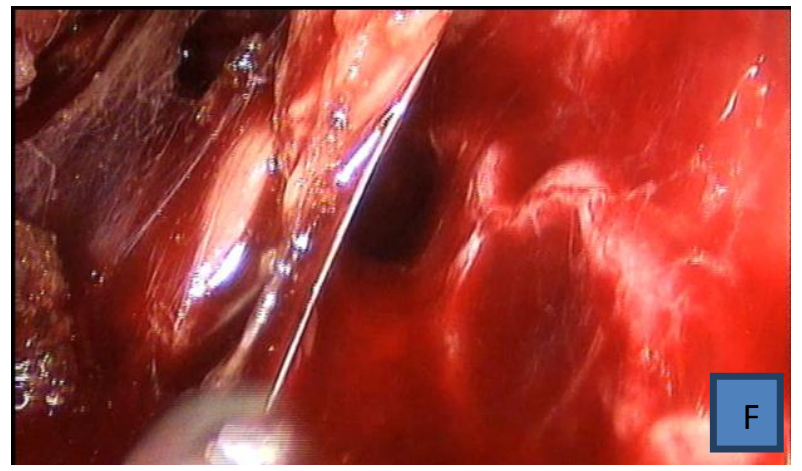

F. Endoscopic view showing left recurrent laryngeal nerve.

\section{Operative Technique}

\section{A. Pre-operative Preparation}

Chlorhexidine mouth wash was given for 2 days prior to surgery.

\section{B. Body Position}

Supine with extended neck position with a sand bag placed in between the shoulders of the patient. 


\section{Procedure}

- One $10 \mathrm{~mm}$ and two $5 \mathrm{~mm}$ laparoscopic ports was inserted into oral vestibule, 10 $\mathrm{mm}$ port being in midline.

- $\mathrm{CO} 2$ insufflated in subplatysmal plane to create a space (pressure $8 \mathrm{mmhg}$ ).

- Strap muscles were separated in midline and retracted using sutures from outside.

- Space was created up to sternal notch inferiorly and laterally up to sternocleidomastoid.

- Isthmus of thyroid was divided in midline.

- Superior pole dissection done and superior thyroidal artery ligated and divided.

- Recurrent laryngeal nerve and inferior parathyroid gland were identified and secured.

- Inferior pole was dissected with and inferior thyroid artery identified, ligated and divided.
- Specimen was mobilised and delivered out through the oral vestibule.

- A 14fr suction drain was kept below the strap muscles and strap muscles approximated with absorbable sutures.

- Oral vestibule was repaired with absorbable sutures.

\section{Observation and Results}

Mean age of our study population was 42.3 years and all the patients in our study population were females. Out of 18 , seventeen patients presented to us with solitary thyroid nodule (Right-11, left6) and one with bilateral multinodular goitre. On USG the average gland size was $3.48 \times 3.54 \times 3.48$ cms with largest being $5 \times 4.6 \times 5.1 \mathrm{~cm}$ sized gland. All of the patients were euthyroid and USG guided FNAC was performed in all of the patients. Out of them, 14 patients had Bethesda grade 2 benign lesions while two each had grad 3 and grade 4 lesions, respectively.

\section{Chart showing size of gland (in cms)}

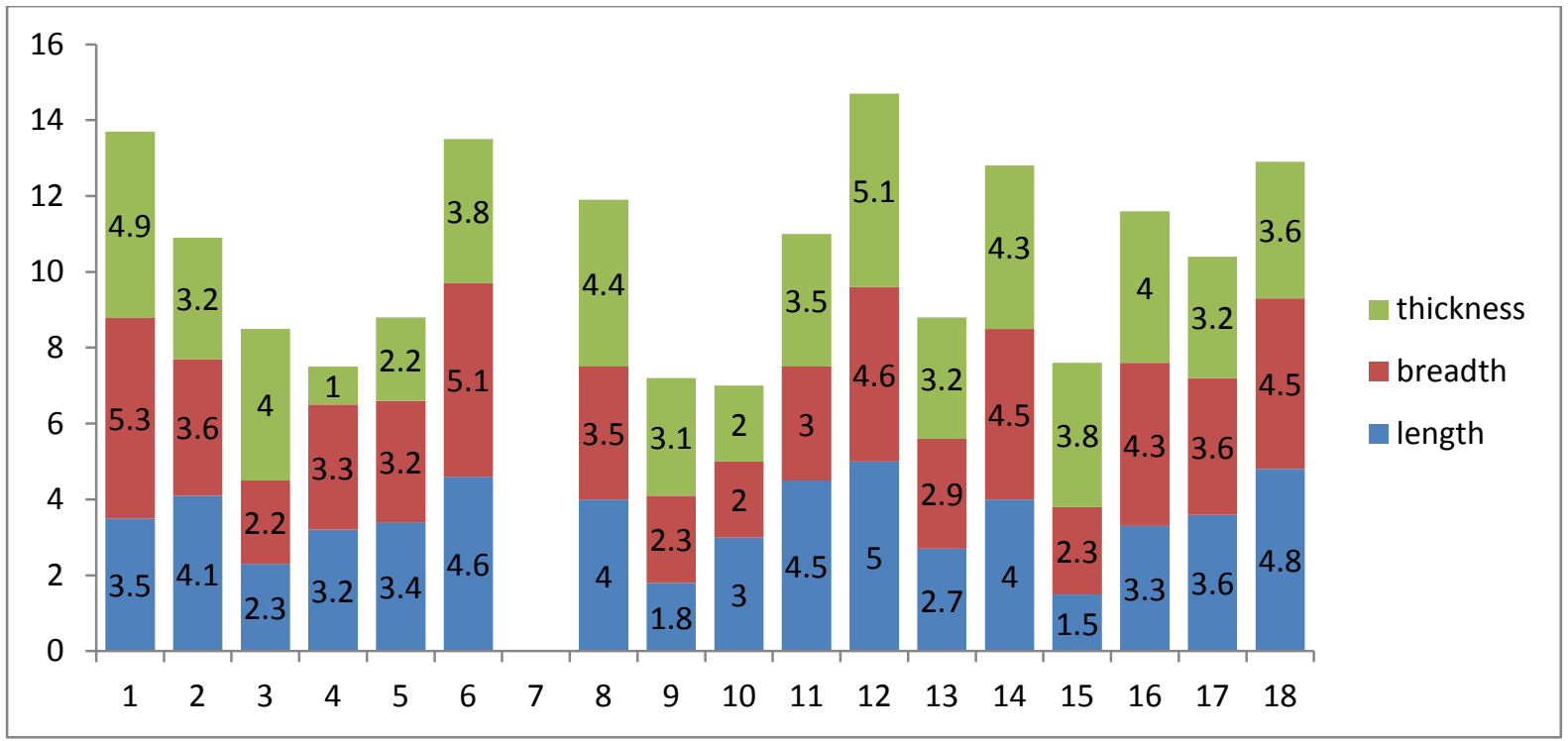

16 patients were successfully operated with Hemithyroidectomy and one with total thyroidectomy while one case was converted to open thyroidectomy due to dense adhesions to surrounding tissue, it was eventually diagnosed as Reidel's thyroidits.
Mean operative time was 164 minutes, which was 210 minutes to start with during early phases of our learning curve and it had gradually come down in later cases. 


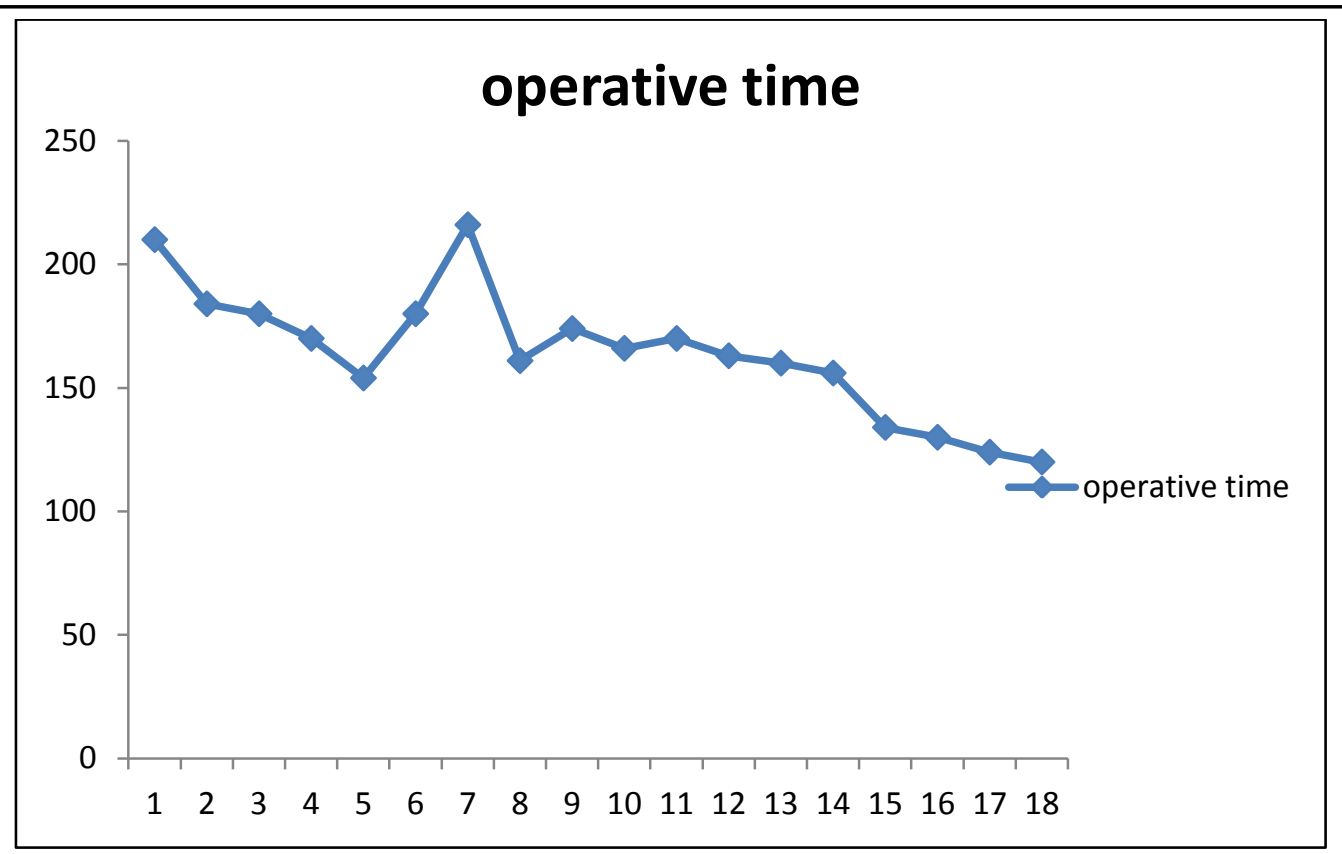

Average blood loss during surgery was $26.7 \mathrm{ml}$ and recurrent laryngeal nerve was identified and secured in all the cases.

On histopatholgy $83.3 \%$ of the patients had benign colloid goitre while two patients had folloicular adenoma and one patient had Reidel's thyroiditis.

Post operative period was uneventful in most of the patients and none of the patients developed surgical emphysema or hoarsenes of voice or hyperparathyroidism in post op period. However one patient developed neck abscess which had to be surgically drained. And one patient complained of paresthesia along lower lip and chin which resolved spontaneously after 2 weeks.

Mean VAS pain score in our study population was 2.4 on post of Day 1, 2.1 on day 2 and 1.2 on day 3 , overall it was 1.9 .

We could achieve acceptable scarless surgery in nearly all of the patients as $83.3 \%$ of our patients had MSS of 5, two had MSS 6 while one patient with neck abscess had MSS 11. 94.4\% of our patients were discharged on POD3 after removal of drain while one patient was discharged on POD 7.

\begin{tabular}{|l|c|c|c|c|c|c|c|}
\hline & $\begin{array}{c}\text { Laterality } \\
\text { (L/R/ bilateral) }\end{array}$ & $\begin{array}{c}\text { Average size } \\
\text { of gland }\end{array}$ & $\begin{array}{c}\text { Mean } \\
\text { operative } \\
\text { time } \\
\text { (min) }\end{array}$ & $\begin{array}{c}\text { Mean } \\
\text { operative } \\
\text { blood } \\
\text { loss(ml) }\end{array}$ & $\begin{array}{c}\text { Conversion to } \\
\text { open } \\
\text { thyroidectomy }\end{array}$ & $\begin{array}{c}\text { Post } \\
\text { operative } \\
\text { scar }\end{array}$ & $\begin{array}{c}\text { VAS } \\
\text { (pain) }\end{array}$ \\
\hline $\begin{array}{l}\text { Our study } \\
\text { (n=18) }\end{array}$ & $5 / 11 / 1$ & $\begin{array}{c}3.48 \times 3.54 \times 3.48 \\
\mathrm{~cm}\end{array}$ & 164 & 26.7 & 1 & 5.3 & 1.9 \\
\hline $\begin{array}{l}\text { Anuwang et } \\
\text { al (n=425) }\end{array}$ & $245 / 177$ & $3.8 \mathrm{~cm}$ & 96.6 & 35.8 & 3 & - & 1.3 \\
\hline $\begin{array}{l}\text { Shiva et al } \\
\text { (n=11) }\end{array}$ & & $23 \mathrm{cc}$ & 126.3 & 1.8 & 0 & - & - \\
\hline $\begin{array}{l}\text { Wang et al } \\
\text { (n=18) }\end{array}$ & \begin{tabular}{l}
$*-$ ishtmectomy \\
\hline
\end{tabular} & $1.58 \mathrm{~cm}$ & 151.6 & 26.9 & 1 & - & - \\
\hline
\end{tabular}


Comparison chart of complication

\begin{tabular}{|l|c|c|c|c|c|c|c|}
\hline & $\begin{array}{c}\text { RLN } \\
\text { injury } \\
(\mathbf{T} / \mathbf{P})\end{array}$ & $\begin{array}{c}\text { SLN } \\
\text { injury } \\
(\mathbf{T} / \mathbf{P})\end{array}$ & $\begin{array}{c}\text { Mental } \\
\text { nerve injury } \\
(\mathbf{T} / \mathbf{P})\end{array}$ & $\begin{array}{c}\text { Hypoparathyroidism } \\
(\mathbf{T} / \mathbf{P})\end{array}$ & Infection & Seroma & Others \\
\hline Our study & 0 & 0 & $1 / 0$ & 0 & 1 & 0 & - \\
\hline Anuwang et al & $25 / 0$ & 0 & $3 / 0$ & $46 / 0$ & 0 & 20 & 1 hematoma \\
\hline Shiva et al & 0 & 0 & 0 & 0 & 0 & 0 & - \\
\hline Wang et al & 0 & $3 / 0$ & $1 / 0$ & 0 & 0 & 0 & - \\
\hline
\end{tabular}

\section{Discussion}

Advances in minimally invasive surgery have led to convergence of various ideas and techniques to find easier, safer and cosmetically better approaches for conventional surgeries. Our approach was one such attempt to provide cosmetically acceptable surgery to patients of thyroid swelling. Endoscopic thyroidectomy has been performed through breast and axillary approach but all it does is hides the scar at a distant place. Through our approach we were able to thyroidectomy of the patients without any visible scar.

Wilhelm and Metzig were the first to perform endoscopic thyroidectomy and had used sublingual approach (Metzig, 2011). Nakajo et al had performed transoral endoscopic thyroidectomy by using K-wires and without using gases (Nakajo A1, 2013). Anuwong published a case series of 425 patients using conventional laparoscopic instruments concluding it as a safe and effective approach (Anuwong, 2018).

$\mathrm{VM} \mathrm{Pai}^{4}$ et al were the first to publish any such experience from India in 2015 (Vishwanath M. Pai, 2015). While Shiva et $\mathrm{al}^{5}$ published a case series of 11 cases.

Ours is the largest case series published so far from India. We could achieve comparable operative time, minimal blood loss and complications in our study.

\section{Conclusion}

- Existing approaches of minimally invasive thyroid surgery requires creation of longer subcutneous tunnel leading to increased post operative complications.
- Shorter distance of thyroid gland from oral vestibule makes it truly a NOTES surgery.

- Transoral endoscopic thyroidectomy through vestibular approach is relaible, replicable and cost effective surgery.

- However a detailed study with large sample size is required to validate our observation.

Consent: Taken from patients for uploading their photos.

Acknowledgments- No grant support for this study. Compliance with ethical standards

Conflict of interest- No conflict of interest in this study.

\section{Bibliography}

1. Wilhelm T, Metzig A (2010) Endoscopic minimally invasive thyroidectomy: first clinical experience. SurgEndosc 24:17571758

2. Nakajo A, Arima H, Hirata M et al (2013) Trans-oral videoassisted neck surgery (TOVANS). A new transoral technique of endoscopic thyroidectomy with gasless premandible approach. Surg Endosc 27:1105-1110.

3. Anuwong A, Ketwong K, Jitpratoom P, Sasanakietkul T, Duh QY (2018) Safety and outcomes of the transoral endoscopic thyroidectomy vestibular approach. JAMA Surg 153(1):21-27.

4. Vishwanath M. Pai, * . P. (2015). Transoral endoscopic thyroidectomy: A case report. IJS case report, 99-101.

5. Sivakumar T, Amizhthu R A, Year : 2018 | Transoral endoscopic total thyroidectomy 
vestibular approach: A case series and literature review, Volume: 14 Issue Number: 2 | Page: 118-123

6. Wang Y, Zhang Z, Zhao Q, Xie Q, Yan H, Yu X, Xiang C, Zhang M, Wang P (2018) Transoral endoscopic thyroid surgery via the tri-vestibular approach with a hybrid space-maintaining method: a preliminary report. Head neck.

7. Beausang E, Floyd H, Dunn KW, et al. A new quantitative scale for clinical scar assessment. Plast Reconstr Surg. 1998; 102:1954-61. 